\title{
Preparation and Characterization of Biochar Derived from Agricultural By-Products for Dye Removal
}

\author{
Phuong Thu Le $\mathbb{D}^{1}{ }^{1}$ Huyen Thuong Bui, ${ }^{1}$ Duy Ngoc Le, ${ }^{1}$ Thi Hue Nguyen, ${ }^{2}$ Le Anh Pham, \\ Hong Nam Nguyen, ${ }^{1}$ Quoc Son Nguyen, ${ }^{1}$ Thu Phuong Nguyen, ${ }^{3}$ Ngóc Trinh Bich, ${ }^{1}$ \\ Thi Thuy Duong, ${ }^{2}$ Marine Herrmann, ${ }^{1,4}$ Sylvain Ouillon $\mathbb{D}^{1,4}$ and Thi Phuong Quynh Le ${ }^{5}$ \\ ${ }^{1}$ University of Science and Technology of Hanoi, Vietnam Academy of Science and Technology, 18 Hoang Quoc Viet Road, \\ Cau Giay, Hanoi, Vietnam \\ ${ }^{2}$ Institute of Environmental Technology, Vietnam Academy of Science and Technology, 18 Hoang Quoc Viet Road, Cau Giay, \\ Hanoi, Vietnam \\ ${ }^{3}$ Institute for Tropical Technology, Vietnam Academy of Science and Technology, 18 Hoang Quoc Viet Road, Cau Giay, \\ Hanoi, Vietnam \\ ${ }^{4}$ UMR LEGOS, Université de Toulouse, IRD, CNES, CNRS, UPS, 14 avenue Edouard Belin, 31400 Toulouse, France \\ ${ }^{5}$ Institute of Natural Products Chemistry, Vietnam Academy of Science and Technology, 18 Hoang Quoc Viet Road, Cau Giay, \\ Hanoi, Vietnam
}

Correspondence should be addressed to Phuong Thu Le; le-phuong.thu@usth.edu.vn

Received 27 August 2021; Revised 30 September 2021; Accepted 1 November 2021; Published 11 November 2021

Academic Editor: Thanh Son Le

Copyright (c) 2021 Phuong Thu Le et al. This is an open access article distributed under the Creative Commons Attribution License, which permits unrestricted use, distribution, and reproduction in any medium, provided the original work is properly cited.

In this study, biochar was derived from the agricultural by-products coconut coir (BC1) and rice husk (BC2) activated with $\mathrm{NaOH}$ 25\%. This material was characterized through analytical methods such as SEM images, XRD, FTIR, and Raman. Analysis results indicated that the carbon structure carbon is amorphous and with many graphene layers. A high specific surface area was detected with $364.22 \mathrm{~m}^{2} \cdot \mathrm{g}^{-1}$ for $\mathrm{BC} 1$ and $329.71 \mathrm{~m}^{2} \cdot \mathrm{g}^{-1}$ for $\mathrm{BC} 2$ with many meso and micropores when analyzed by $\mathrm{N}_{2}$ and $\mathrm{CO}_{2}$ adsorption. The material also showed anionic and cationic dye adsorption capacity for textile wastewater following both Langmuir and Freundlich models where BC2 had better max adsorption capacity compared to $\mathrm{BC} 1,6.519 \mathrm{mg} . \mathrm{g}^{-1}$ for $\mathrm{MO}$ and $8.612 \mathrm{mg}^{-1} \mathrm{~g}^{-1}$ for $\mathrm{MB}$.

\section{Introduction}

Textile is one of the largest industries in the globe. Vietnam was ranked 8th in exporting textile and dye products in 2018 according to the WTO, which provided over 1.6 million employments [1]. However, this industry emits huge amounts of wastewater that need to be treated. Many solutions such as biological treatments [2, 3], electrocoagulation [4-6], membrane bioreactors [7-9], or photochemical methods [10] have been developed. [11] combined a coagulation-flocculation treatment with alkali-activated carbon made from sand with a TAN efficiency of 70\%. Compared to other methodologies, many studies have confirmed that adsorption methods with activated carbon from agricultural by-products are highly effective when treating textile dyeing wastewater.

Various studies have shown that agricultural byproducts such as straw, rice husks, corn cobs, or coir have a high potential for adsorption of pollutants, especially pesticides and dyes in wastewater $[12,13]$. The superiority of these types of material lies in the fact that it is inexpensive or even free, is available in abundance, especially in countries with strong agricultural economies like Vietnam, and is easily biodegradable in the environment. Vietnam is classified among the top five rice-producing countries in the world with an output of 38 million tons.year ${ }^{-1}$ (GSO, 2009), equivalent to 38 million tons of straw and 6-7 million 
tons of rice husks. Common agricultural by-products from rice production straw, rice husk ash, and rice hulls [14] have all be shown to be beneficial in removing pesticides [14-16] and dyes [17-19]. Rice husk-derived biochar has also been studied and applied to remove contaminants from polluted water with an adsorption capacity of $123.03 \mathrm{mg}^{-1}$ for glyphosate [20] and $9.73 \mathrm{mg} \cdot \mathrm{g}^{-1}$ for the methylene blue [21].

In addition to rice, Vietnam is also known as one of the ten largest manufacturers of coconut-related products in the world with an output of around 1.5 million tons in 2017, the second-largest producer of coir in the world with 36,000 tons in 2017 (FAO,2018). The primary by-product of coconut is coconut shell which has a high adsorption capacity and is hence widely used in biofilter systems for the purpose of pesticides removal [22-24]. Other studies have proven its usefulness in textile wastewater treatments [25-27]. Results all showed that biochar has a high ability to remove pollutants in general. The vast majority of agricultural byproducts are lignocellulose materials composed largely of polysaccharides (cellulose and hemicelluloses) and lignins with a chemical composition of hydroxyl and carboxyl groups [28]. Interactions between these functional groups and pesticides are also expected to be the primary mechanism for adsorption of agricultural by-products [29]. Agricultural by-products have received much attention from scientists as a source for biochar [30]. For a long time, combining biochar with the right measurement of soil has been used to increase the water holding capacity as well as soil nutrients and crop yield [31]. Furthermore, recent studies have demonstrated the high efficiency and feasibility of biochar-soil blending at laboratory and field scales for the purpose of preventing glyphosate-containing pesticides in soil from leaking into natural water sources [32-35]. However, De Gisi et al. [36] showed that there is a lack of data concerning the characteristics of the new by-products studied such as their average particle size or specific surface area.

With the abundance of input materials as well as the necessity to recycle such a valuable agricultural waste, biochar derived from rice husk and coconut coir is expected to be the answer to the demand for an economically and environmentally friendly material that has effective pollutants adsorption ability for application in surface water treatment.

In this study, biochar was prepared in the laboratory from agricultural by-products in Vietnam such as coconut coir (named BC1) and rice husks (named BC2) by a pyrolysis method to investigate its potential in water pollution treatment. To be more specific, this research is designed to test the adsorbability of the biochar towards two different dyes, i.e., methylene blue-a cationic dye, and methyl orange-an anionic dye.

\section{Chemicals and Methodology}

2.1. Chemicals. Methylene blue trihydrate (MB, $\mathrm{C}_{16} \mathrm{H}_{18} \mathrm{ClN}_{3} \mathrm{~S} .3 \mathrm{H}_{2} \mathrm{O}, \geq 98.5 \%$ ) - a cationic dye and methyl orange ( $\mathrm{MO}, \mathrm{C}_{14} \mathrm{H}_{14} \mathrm{~N}_{3} \mathrm{NaO}_{3} \mathrm{~S}, \geq 98.5 \%$ ) - an anionic dye represent both types of separate functional group and were purchased from Xilong Chemical Co., Ltd. (China). We used sodium chloride $(\mathrm{NaCl}, \geq 99.5 \%)$ and sodium hydroxide
( $\mathrm{NaOH}, \geq 99.5 \%)$ from Merck (Germany), and hydrochloric acid $(\mathrm{HCl}, 35.0-37.0 \%)$ and nitric acid $\left(\mathrm{HNO}_{3}, 65 \%\right)$ from Daejung chemicals and metals (Korea).

\subsection{Methodology}

2.2.1. Biochar Production. Rice husk was collected from Bac Ninh province, Northern Vietnam, and thoroughly sieved to keep only the $5 \mathrm{~mm}$ diameter husk for use. Coconut fiber was collected from Hoai Duc district, Hanoi city, cut into small pieces, and sieved into coir less than $2 \mathrm{~mm}$ and more than $1 \mathrm{~mm}$ in diameter.

Rice husk and coconut coir were carefully washed three times with tap water and twice with distilled water to remove impurities. After that, the coir and the husk were dried at $105^{\circ} \mathrm{C}$ in the oven for 5 hours until they were completely dried. The husk (or coir) was then placed in a stainless steel pot and covered on the surface with commercial charcoal to prevent the formation of ash and coke during carbonization. Next, the pot was sealed and put into the Nabertherm furnace (Germany) under limited oxygen conditions. The material heating program used is shown in the diagram in Figure 1. At the end of the carbonization, the biochars' weight, density, and mass loss (\%) were calculated (Table 1).

Biochar after carbonization is activated by $\mathrm{NaOH} 25 \%$ : biochar's specific surface area, ion-exchange capacity, and the number of oxygen-containing functional groups all raise after it is treated with $\mathrm{NaOH}[37,38]$. It can simultaneously be used as an effective, inexpensive, and ecologically acceptable activator [39]. A mixture of $18 \mathrm{~g}$ biochar and $300 \mathrm{~mL}$ of $\mathrm{NaOH} 25 \%$ solution were thus added into a Duran bottle of $500 \mathrm{~mL}$, and the mixture was shaken at $250 \mathrm{rpm}$ in an IKA KS 4000i incubator shaker for 4 hours at room temperature. The material was then filtered out and washed with distilled water (with a conductivity less than 18 megaohms), dried naturally at room temperature, and stored in a brown bottle.

2.2.2. Characterization of Biochars. A temperature-induced mass loss of $0.7 \mathrm{~g}$ each raw material (rice husk and coconut shell) was determined by thermogravimetric analysis and differential gravimetric analysis (TGA/DTG) using a CIRAD-designed Macro-TGA from $25^{\circ} \mathrm{C}$ to $800^{\circ} \mathrm{C}$ at a heating rate of $5^{\circ} \mathrm{C} \cdot \mathrm{min}^{-1}$ under air. Every 5 seconds, mass loss data and temperature changes were recorded by the MTG software and analyzed on the Origin software. The functional groups and characterizing covalent bonding information of the different biochars after the pyrolysis were analyzed by FT-IR spectrometer (Thermo scientific iS50). Information on the crystal structure, phase, orientation, and molecular interactions of the biochars after fabrication were studied on the Equinox 5000-XRD Spectrometreler and the Raman spectrometer NRS-5100 from JASCO Corporation, Japan. The surface morphology and porous structure were observed by a scanning electron microscope (SEM, Hitachi S-4800). This instrument is also integrated with Energy Dispersive X-ray Spectroscopy for the analysis of the surface elemental composition of materials.

$\mathrm{N}_{2}$ and $\mathrm{CO}_{2}$ adsorption isotherms of samples processed under vacuum conditions at $300^{\circ} \mathrm{C}$ were analyzed. The 


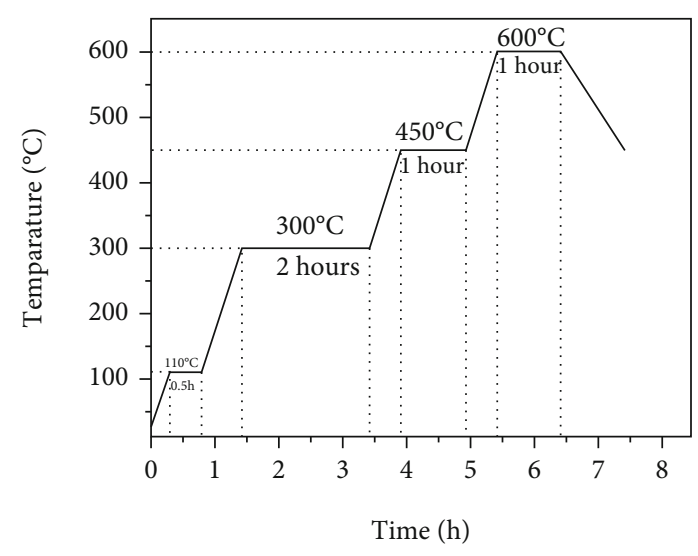

FIGURE 1: Biochar production process diagram.

TABle 1: Density and weight loss of each material before and after carbonization.

\begin{tabular}{lccc}
\hline Material & $\begin{array}{c}\text { Density before } \\
\text { carbonization } \\
\left(\mathrm{g} \cdot \mathrm{mL}^{-1}\right)\end{array}$ & $\begin{array}{c}\text { Density after } \\
\text { carbonization } \\
\left(\mathrm{g} \cdot \mathrm{mL}^{-1}\right)\end{array}$ & $\begin{array}{c}\text { Weight } \\
\text { loss (\%) }\end{array}$ \\
\hline $\begin{array}{l}\text { Coir/biochar 1 } \\
\text { Husk/biochar }\end{array}$ & 0.1309 & 0.1044 & 60 \\
2 & 0.2259 & 0.1309 & 57 \\
\hline
\end{tabular}

measurement was performed by a Belsorp minill MicrotracBEL device at $-196^{\circ} \mathrm{C}$ (for $\mathrm{N}_{2}$ sorption) and $25^{\circ} \mathrm{C}$ (for $\mathrm{CO}_{2}$ sorption), pressure 1 bar. The Belsorp software (BEL master TM) was used to analyze the porosity properties of carbon materials. Application of $\mathrm{N}_{2}$ adsorption isotherm by the BET equation and graph data allowed calculation of the specific surface area, total pore volume, and micrometer-sized pore distribution. The $\mathrm{CO}_{2}$ adsorption isotherm by the Dubinin-Astakhov (DA) method was used to determine the pore volume of the sample.

To determine pHpzc, two different solutions of sodium chloride $(\mathrm{NaCl})$ were prepared at $10^{-2} \mathrm{M}$ and $5 \times 10^{-2} \mathrm{M}$ with purged deionized water $\left(\mathrm{CO}_{2}-\right.$ free $)$ and adjusted with pure hydrochloric acid $(\mathrm{HCl})$ and pelleted sodium hydroxide $(\mathrm{NaOH})$ to different $\mathrm{pH}$ values, i.e. $2,4,6,8,10$, and 12 . Then, each biochar was added into separated bottles at a ratio of $5 \mathrm{~g}$ of biochar to $1 \mathrm{~L}$ of $\mathrm{pH}$-adjusted sodium chloride solution of $70 \mathrm{~mL}$ total. The bottles were secured in the incubator shaker for 24 hours. After shaking, the $\mathrm{pH}$ value was recorded in order to sketch an initial and final $\mathrm{pH}$ diagram.

2.2.3. Adsorbability of Biochars. $\mathrm{MB}$ and $\mathrm{MO}$ dyes were used to study the adsorption capacity of the biochar prepared at room temperature. These experiments were carried out in a $70 \mathrm{~mL}$ solution containing a $10 \mathrm{mg} \cdot \mathrm{L}^{-1}$ dye solution and a $5 \mathrm{mg} . \mathrm{L}^{-1}$ biochar in a $100 \mathrm{~mL}$ Duran bottle. The initial $\mathrm{pH}$ was chosen based on the $\mathrm{BC}$ pHpzc data adjusted by using a solution of $\mathrm{H}_{2} \mathrm{SO}_{4}$ and $\mathrm{NaOH}$. A mixing series was set up, and the solution was shaken in the incubator shaker IKA KS 4000i at $250 \mathrm{rpm}$. All experiments were carried out at room temperature. Each sample was collected after 2 hours. The adsorbents were centrifuged in Hermle centrifuge $\mathrm{Z} 366 \mathrm{~K}$ at $4500 \mathrm{rpm}$ for 20 minutes, separated by Whatman cellulose acetate paper with a pore size of $0.45 \mu \mathrm{m}$, and dried at $105^{\circ} \mathrm{C}$ for 2 hours. The concentration changes of the dye solutions were measured by Shimadzu UV-1800 UV-Vis spectrometer.

2.2.4. Determination of $M B$ and $M O$ Concentrations by UVVis Spectrophotometry. For the study of MB removal efficiency, the absorbance of the samples at maximum wavelength $\lambda_{\max }=664 \mathrm{~nm}$ was measured. Calibration curves for MB were prepared with 7 different standard concentrations ranging from $0 \mathrm{mg} . \mathrm{L}^{-1}$ to $12 \mathrm{mg} . \mathrm{L}^{-1}$. Since the color of $\mathrm{MO}$ is $\mathrm{pH}$-dependent, the absorbance of the solution was measured at $\lambda_{\max }=507 \mathrm{~nm}$ for $\mathrm{pH}=2$, and at $\lambda_{\max }=464 \mathrm{~nm}$ for both $\mathrm{pH}=12$, the natural $\mathrm{pH}$ value of the solution.

The $H$ removal efficiency (\%) can be calculated based on the dye concentration:

$$
H=\frac{C_{0}-C_{t}}{C_{0}} \times 100
$$

where $C_{0}$ and $C_{t}$ are the dye concentrations at initial time and time $t$, respectively.

According to Lamber Beer's law: $\mathrm{Abs}=\varepsilon \mathrm{bC}$, the dye concentration $C$ is directly proportional to the absorbance since the molar attenuation coefficient $\varepsilon$ and the path length $b$ (size of cuvette) remain constant. Therefore, the $H$ removal efficiency (\%) can be calculated based on the absorbance of the solution:

$$
H=\frac{\mathrm{Abs}_{0}-\mathrm{Abs}_{t}}{\mathrm{Abs}_{0}} \times 100
$$

where $\mathrm{Abs}_{0}$ and $\mathrm{Abs}_{t}$ are the absorbances measured at initial time and time $t$, respectively.

Batch adsorption experiments for MB and MO removal were conducted in triplicates. In this study, the $\mathrm{pH}$ value of the research samples was determined by Hana instrument HI98197 portable multiparameter meter according to TCVN 6492:2011, ISO 10523:2008.

\section{Results and Discussion}

3.1. TGA/DTG and Biochar Density. The biochar carbonization process was set up based on the result of TGA/DTG analysis, shown in Figure 2.

The TGA/DTG diagram shows the mass loss curves of both materials (coir and husk) as a function of temperature at the heating rate of $5^{\circ} \mathrm{C} \cdot \mathrm{min}^{-1}$. The materials were dried before carbonization, so in the temperature range from $100^{\circ} \mathrm{C}$ to $250^{\circ} \mathrm{C}$, the mass does not change much, indicating the absence of free water molecules in the materials. The biggest mass loss occurs at $250-300^{\circ} \mathrm{C}$, with a loss greater than $60 \%$ and $40 \%$ for coir and husk, respectively, suggesting that water and bounds organic compounds have been decomposed. In the temperature range of $300^{\circ} \mathrm{C}-450^{\circ} \mathrm{C}$, the pyrolysis process continues at a slower rate, with the final yield reaching about $5 \%$ for coir and $25 \%$ for husk. Both 


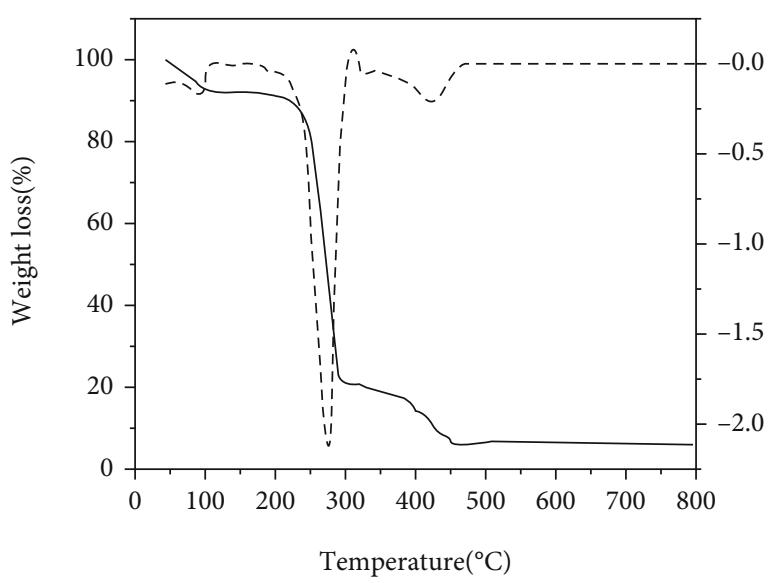

(a)

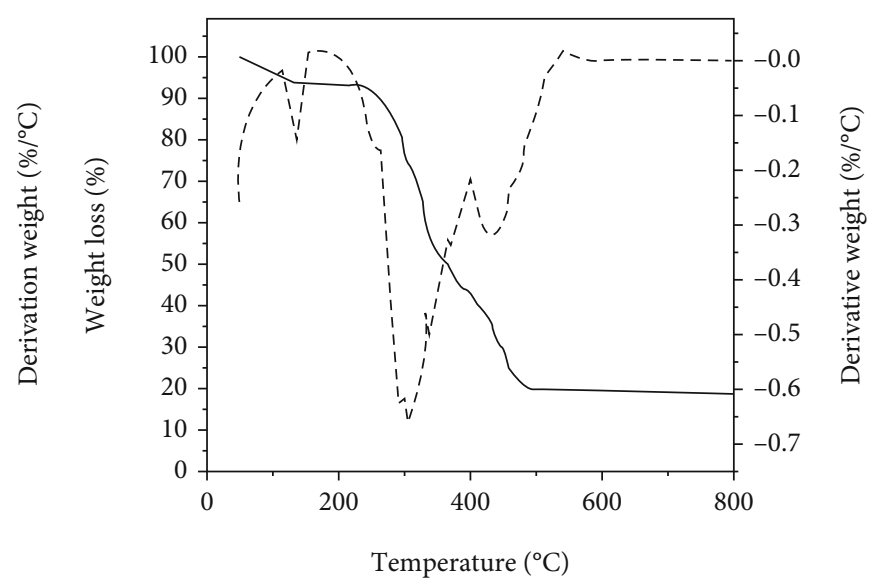

- TGA

(b)

FIgURE 2: DTG/TGA diagram of coir (a) and rice husk (b).

TGA/DTG diagrams of coir and husk indicate that the mass yield hardly changes at temperatures above $450^{\circ} \mathrm{C}$, which suggests that only ash remains.

These results show that although the DTG/TG curve of husk is a little different from that of coir, they are very similar at the first order, which justifies that the same calcination process was used for both materials (Figure 1).

Before and after the carbonization process, each mass and volume of each material were measured to calculate the initial and final density (before/after carbonization). The density of each material is recorded in Table 1.

There is no common pattern for the variation of density of the two materials before and after the carbonization process. For coconut coir (biochar 1 or BC1) and husk (biochar 2 or BC2), the density decreases by $20 \%$ and almost $50 \%$, respectively. This is due to the fact that during calcination, water and organic compounds bound in the structure of the material were lost in gases and water vapor. However, the shape of the coconut coir (BC1) and the husk (BC2) was not altered much after the carbonization process, especially for the husk (which retained the shape of rice grains). Therefore, the density of both materials decreased slightly.

As can be seen clearly from Table 1 , the actual mass loss after the carbonization of coir and husk was only $60 \%$ and $57 \%$, respectively, much lower than when doing the TGA/DTG analysis (respectively, 95\% and 75\%, Figure 2). This can be explained by the formation of ash during TGA/DTG analysis, while during calcination, ashes were significantly reduced by covering the surface material with coal in the calcination process.

3.2. Point of Zero Charge (PZC). The $\mathrm{pH}$ of the solution (methylene blue and methyl orange) has a great influence on the adsorption capacity of the adsorbent on the adsorbate [40]. In order to optimize this capacity, the point of zero charge (PZC) should be analyzed and used. When $\mathrm{pH}$ values are below the PZC of an adsorbent, anions are attracted to its surface; cations experience the same effect when $\mathrm{pH}$ values exceed the PZC [41]. Therefore, several experiments were carefully carried out to determine the PZC value for three types of biochar made from coir of two different sizes and from husk. The results on PZC are shown in Figures 3(a) and $3(\mathrm{~b})$.

A buffer solution was used for the determination of PZC: a solution of $\mathrm{NaCl}$ with $\mathrm{NaOH}$ or $\mathrm{HCl}$ provided a buffer to stabilize and ensure the desired $\mathrm{pH}$ values so that the $\mathrm{PZC}$ result was correct.

For initial $\mathrm{pH}$ values of 2 and 12, the final $\mathrm{pH}$ values were almost identical to the initial values. Differences were only observed for initial $\mathrm{pH}$ values of 4,6 , and 10 , where the final $\mathrm{pH}$ values remained stable around 9. This indicated that biochar 1 has an estimated $\mathrm{PZC}$ value at $\mathrm{pH}=9$, at which the biochar surface reaches electrically neutral state. In addition, according to the $\mathrm{PZC}$ theory, at $\mathrm{pH}$ values above the $\mathrm{PZC}$ value, the materials are negatively charged, and vice versa for $\mathrm{pH}$ values below the PZC.

For biochar 2, the initial-final $\mathrm{pH}$ curve is also similar to that of biochar 1; however, the PZC obtained for biochar 2 was lower than that of the biochar 1 , at $\mathrm{pH}=8$.

3.3. Fourier-Transform Infrared Spectroscopy (FTIR). All FTIR spectra of the obtained biochars were collected in the midinfrared from $4000 \mathrm{~cm}^{-1}$ to $390 \mathrm{~cm}^{-1}$ and are shown in Figure 4.

The two spectra showed similarities, in the single bond region, a wideband showing up at $3500 \mathrm{~cm}^{-1}$ attributed to the $\mathrm{O}-\mathrm{H}$ stretching mode of hydroxyl groups, and in the double bond region. At about $1650 \mathrm{~cm}^{-1}$, the adsorption band was attributed to $\mathrm{C}=\mathrm{O}$ stretching. For the spectrum of biochar 2, the greatest bands were observed at $1050 \mathrm{~cm}^{-1}$, which was in the fingerprint region, and it was attributed to the $\mathrm{C}-\mathrm{O}$ stretching. In the wavenumber range of $900 \mathrm{~cm}^{-1}$ to $400 \mathrm{~cm}^{-1}$, the spectrum was quite complex and hard to observe. However, in particular, when observing the spectrum of biochar 2, some peaks could be clearly seen at 1087, 800, and $460 \mathrm{~cm}^{-1}$, which were attributed to the carbon-silicon 


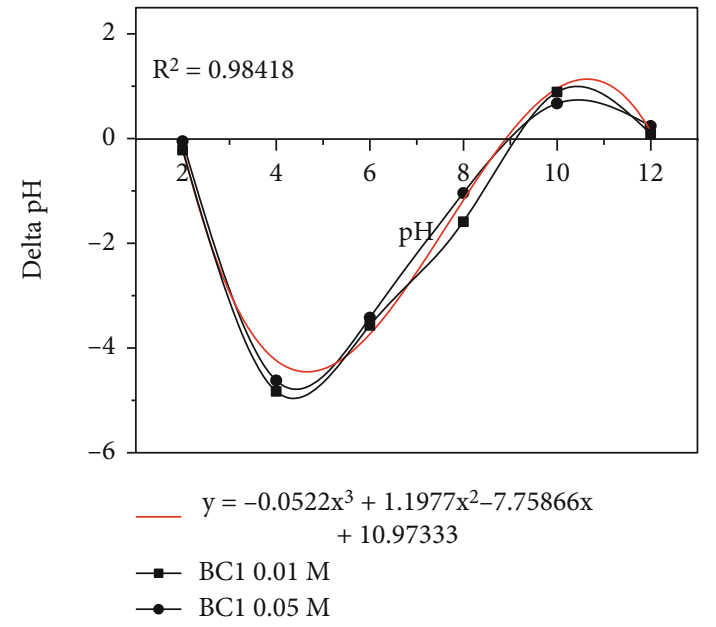

(a)

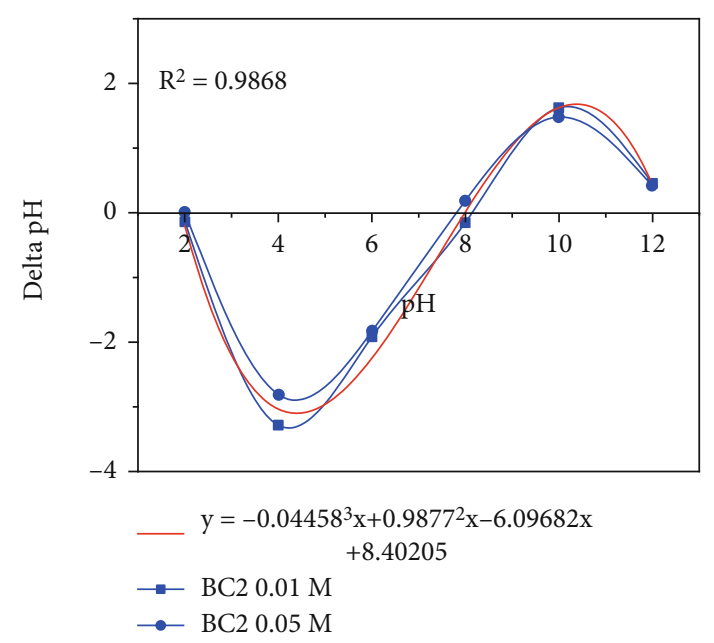

(b)

Figure 3: PZC of $\mathrm{BC} 1$ (a) and PZC of BC2 (b) in a buffer solution containing, respectively, $0.05 \mathrm{M}$ and $0.01 \mathrm{M} \mathrm{NaCl}$.

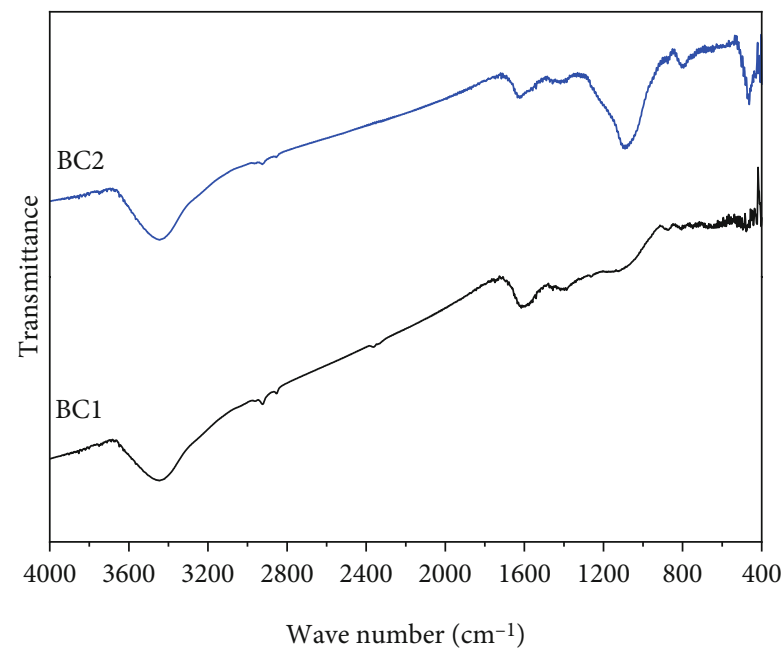

FIGURE 4: FTIR analysis on the biochar.

group (C-Si) (Pankaj $[42,43])$. This carbon-silicon group is often found on the husk surface and is not found in coir. The spectra of biochar 1 did not show many differences. Besides the two spectral bands observed at $3500 \mathrm{~cm}^{-1}$ and $1650 \mathrm{~cm}^{-1}$, the fingerprint region was also complex and hard to assign.

3.4. X-Ray Diffraction Spectroscopy (XRD) Results. The diffraction diagram of the biochars is presented in Figure 5. Two wide peaks range at $2 \theta=22.5^{\circ}$ and $2 \theta=43^{\circ}$ and the absence of peak showing the formation of the crystal phase indicates that the BCs were amorphous carbon. In addition, the diagrams revealed the presence of graphene structure in all biochar samples. The formation of graphene structures can occur during the pyrolysis of materials derived from agricultural by-products [44]. This result is similar to the conclusions of BC diffraction studies from [44]. The diagram also showed that graphene is the only crystal structure that appears in the BCs. In other words, no crystal structure of

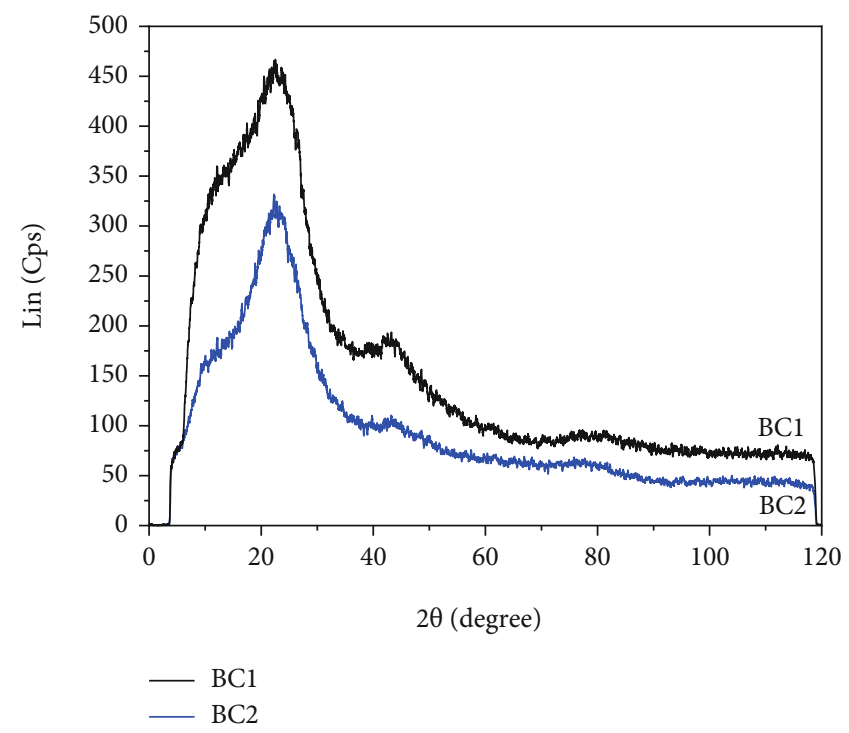

Figure 5: Diffraction diagram of biochars 1 and 2.

other metals could be found on the BC samples. Many studies have also shown that silica compounds in rice husk can form crystals when the temperature reaches $800^{\circ} \mathrm{C}$.

3.5. Raman Spectrum. The carbon structure of biochar was also determined using Raman spectroscopy, complementing the results obtained from XRD (Figure 6).

Raman spectroscopy showed two main peaks at $\mathrm{D}$ band $\left(1361 \mathrm{~cm}^{-1}\right)$ and $\mathrm{G}$ band $\left(1591 \mathrm{~cm}^{-1}\right)$, corresponding to the graphene layer edge and an ideal lattice carbon, respectively [45]. Both peaks showed the presence of carbon atoms $\left(s p^{2}\right)$ in an aromatic compound that corresponds to the amorphous form of the benzene ring $[46,47]$. Despite being different raw materials, the two biochars derived from rice husk and coir had the same shape spectrum, proving that the formation of biochar structure by pyrolisis from different agricultural by-products is the same. This result was also 


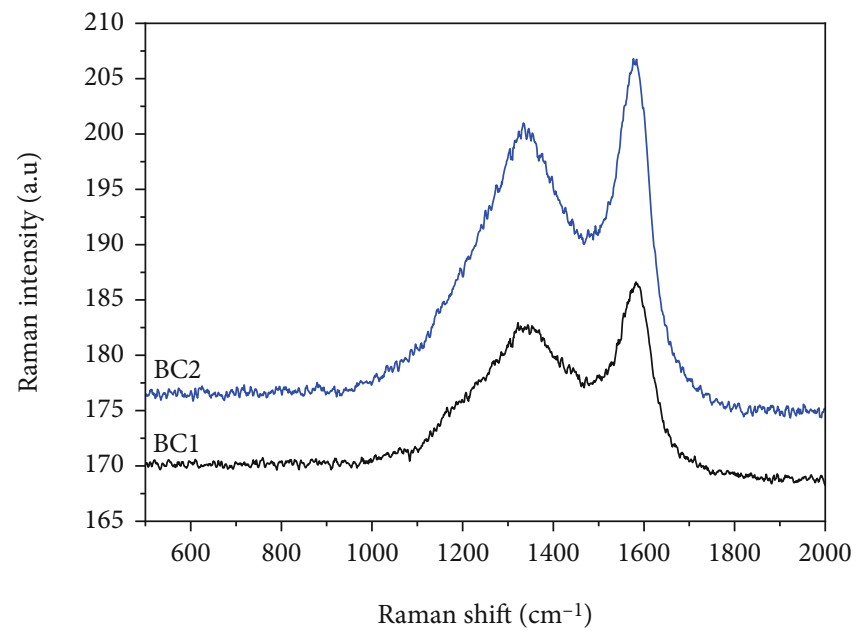

FIgURE 6: Raman spectrum of difference BCs.
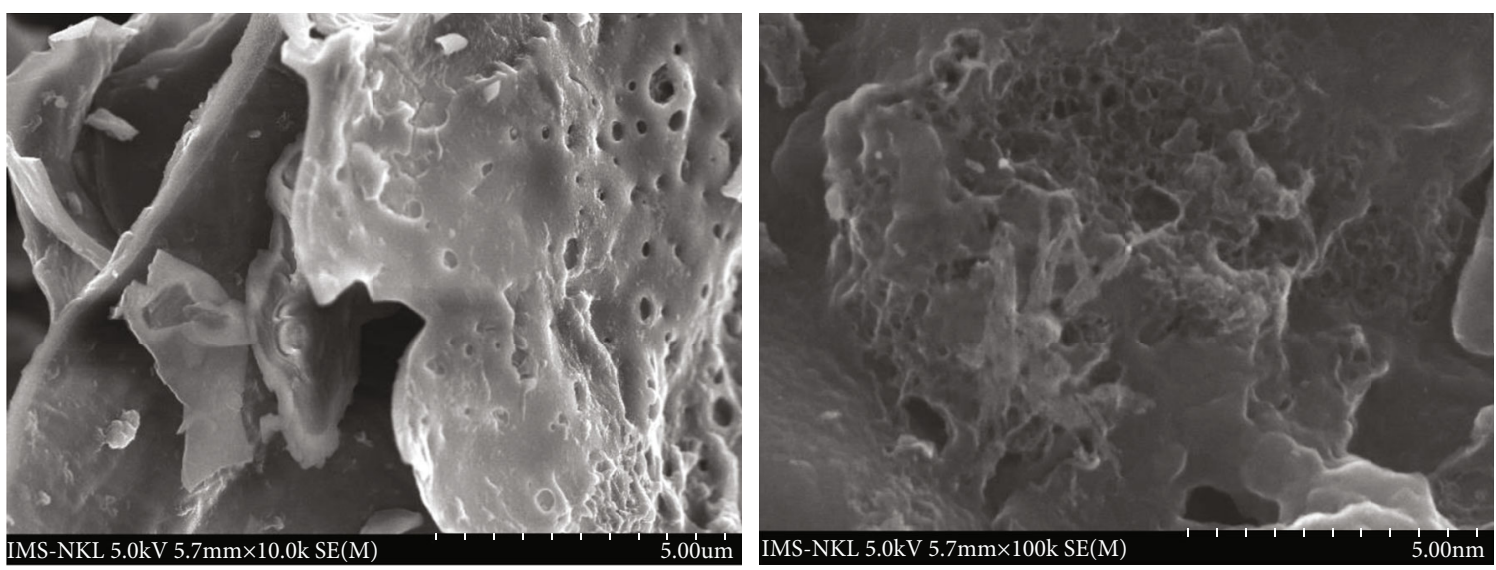

Figure 7: SEM images of BC1.

confirmed by the X-ray diffraction method of biochar. Biochar after pyrolysis has an amorphous form with several layers of graphene to create the porous structure of the material.

3.6. Surface Morphology of Biochars. Surface morphology and porous structure are important features in the adsorption process. In particular, for biochar, solids are obtained from the pyrolysis of rice husks and coir in an anaerobic environment (lack of oxygen and high pressure). The surface morphology, as well as the main surface elemental composition, was investigated by scanning electron microscopy (SEM) (Figures 7 and 8) and energy dispersive X-ray emission (EDX).

Generally, all BCs had porous meso and micropore structures with different shapes and sizes. SEM image observation of both $\mathrm{BC}$ types also showed the structure of the graphene layers formed along with the field structure of BC. These results also correspond to the results of [44].

The SEM image of rice husk biochar (BC2) showed that it remained intact in its structure (fiber shape) of the original husk, and the pores were fairly uniform. After being broken in half, the cross-section image of $\mathrm{BC} 2$ revealed a series of pores with a capillary structure on the BC2 wall, about 5 to $10 \mu \mathrm{m}$ in diameter. Besides, although the mesopore structure was uneven, the micropore size was quite uniform with a diameter of approximately $50 \mathrm{~nm}$.

In contrast, the results for $\mathrm{BC} 1$ yielded a greater variety of pore sizes. Specifically, the surface morphology of biochar from coconut coir showed many pores of fairly nonuniform size with a large structure.

The average percentage values of surface elemental composition in biochars, corresponding to the SEM micrographs analysis positions and dispersive spectrum are presented in Figure 9 and Table 2.

The obtained results showed that the main component of all BCs was carbon, which confirmed the decomposition of cellulose, lignin, and organic matters contained in agricultural by-products at high-temperature $500-600^{\circ} \mathrm{C}$. Besides, they revealed a significant content of oxygen. Combined with the results of the FTIR analysis, the oxygen content in the BCs was confirmed to come from the functional groups -COOand $-\mathrm{OH}$ existing on the surface of BCs. Specifically, Si content included in the $\mathrm{BC} 2$ structure was consistent with the results 

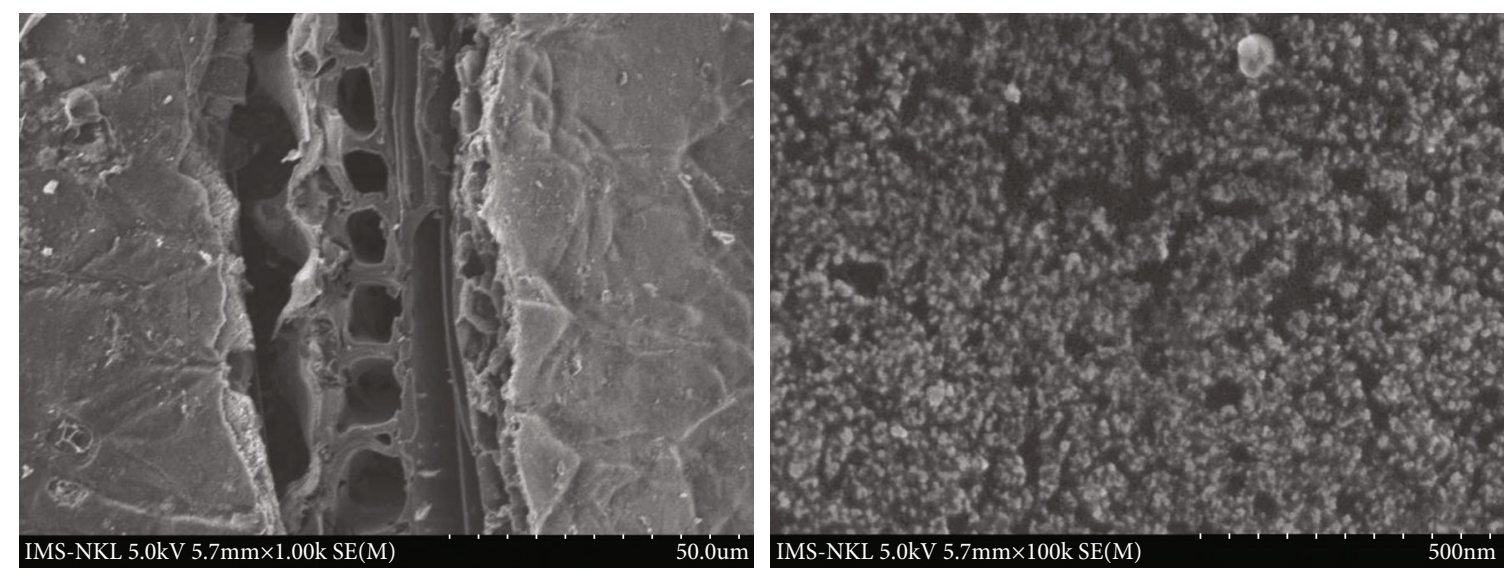

Figure 8: SEM images of BC2.

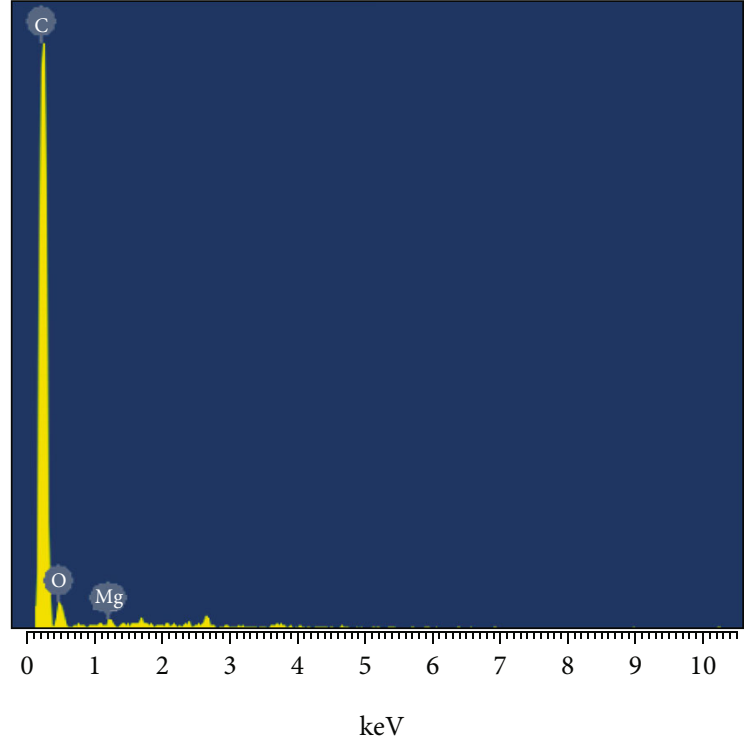

(a)

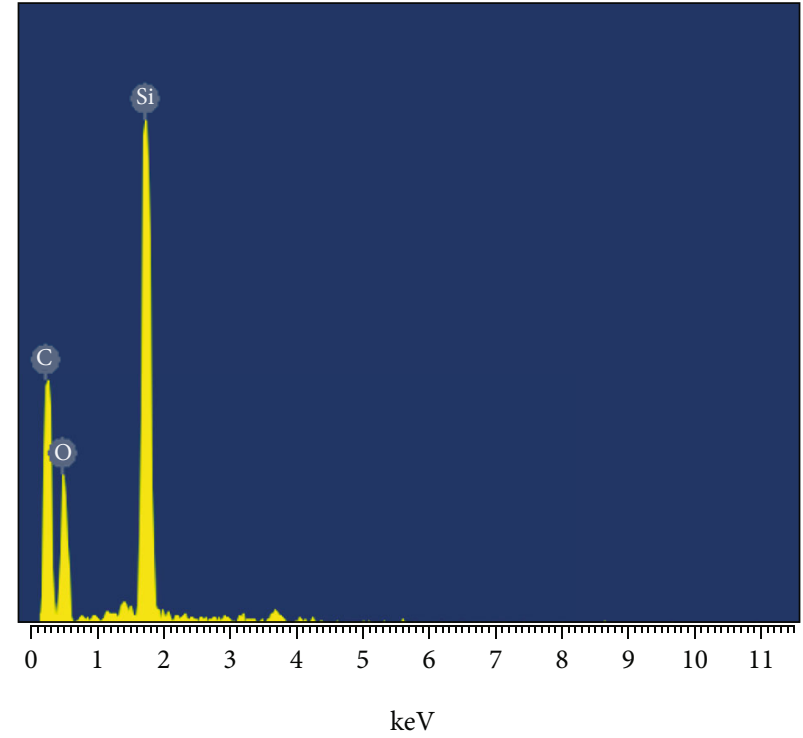

(b)

FIGURE 9: Energy dispersive spectrum corresponding to a SEM image analysis position of BC1 (a) and BC2 (b).

TABLE 2: Average mass percentage of surface elemental composition in biochar.

\begin{tabular}{lcc}
\hline Components & BC1 & BC2 \\
\hline C K (\%) & 82.93 & 40.27 \\
O K (\%) & 16.76 & 44.92 \\
Mg K (\%) & 0.31 & 0.00 \\
Si K (\%) & 0.00 & 14.81 \\
Total & 100.00 & 100.00 \\
\hline
\end{tabular}

of the FTIR analysis, indicating the bond between silicon and carbon (Si-C). However, the contents of $\mathrm{C}, \mathrm{O}$, and $\mathrm{Si}$ are unevenly distributed at different locations of the BCs.

3.7. Specific Surface Area and Pore Volume. The $\mathrm{N}_{2}$ adsorption-desorption isotherms (Figure 10) were used to determine the porosity of the BCs. The specific surface area and pore volume are significant parameters that have a strong link with the adsorption ability of the material. Micropores (diameter $<2 \mathrm{~nm}$ ) and mesopores (between 2 and $50 \mathrm{~nm}$ ) actively participate in the sorption capacity of biochar, while larger pores usually have a much smaller effect [48].

The BC2 had a higher microporosity compared to that of the $\mathrm{BC} 1$, as shown by the higher position of the corresponding isotherm and the larger slope at relative pressures $p / p_{o}$ above 0.1 . The $\mathrm{N}_{2}$ adsorption-desorption isotherm of the $\mathrm{BC} 1$ exhibited type I isotherms in the IUPAC classification [49], which indicated that the microporous structure was dominant in the BC1. Meanwhile, the BC2's isotherms exhibited type IV with a large range for the hysteresis loop. This can be explained by the capillary condensation phenomenon, whereby a gas in a pore condenses into a liquid phase at a pressure $p<p_{o}$ of the bulk liquid [49]. This result strongly suggests that in the case of $\mathrm{BC} 2$, besides micropores, mesopores were also present. 


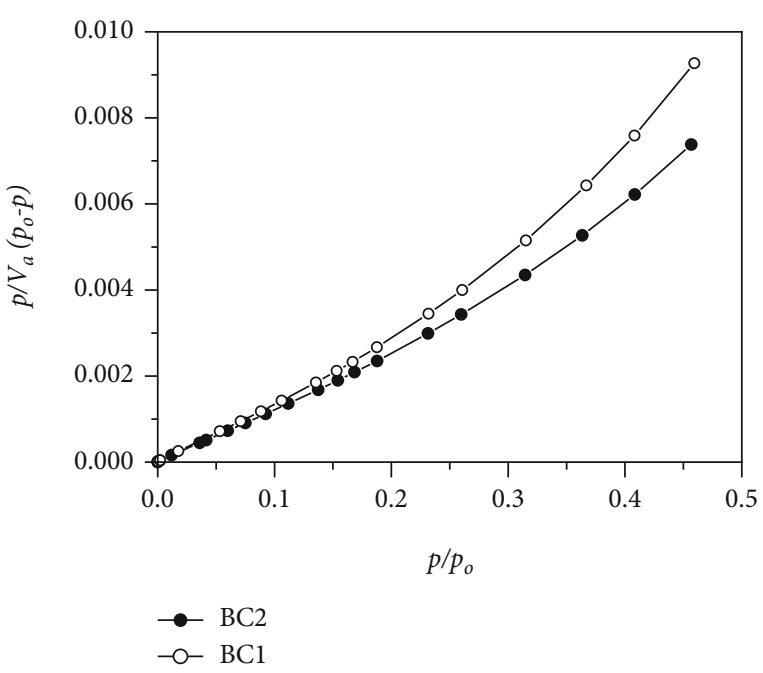

(a)

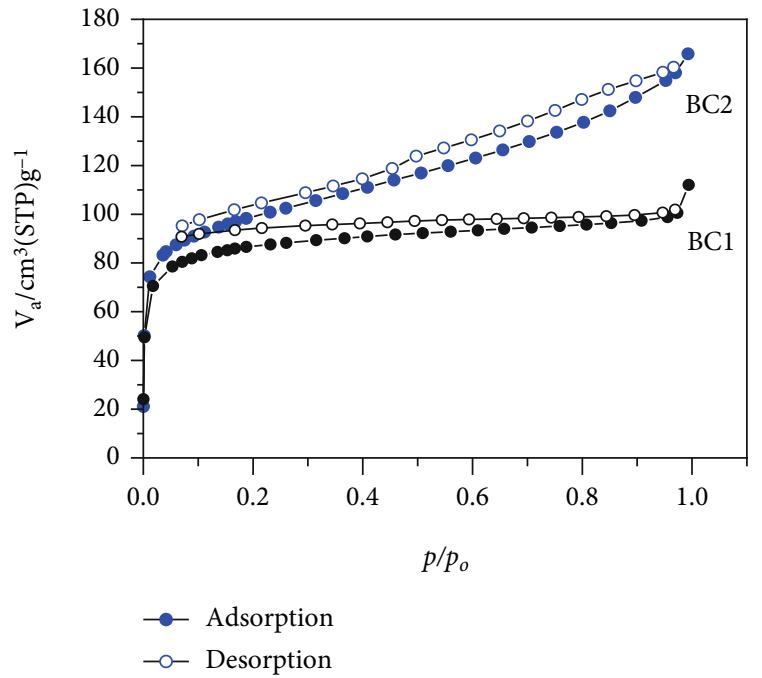

(b)

Figure 10: BET-plot (a) and adsorption/desorption isotherm (b) of BC1 and BC2 in $\mathrm{N}_{2}$.

TABle 3: Parameters of specific surface area and pore of biochar.

\begin{tabular}{lccccc}
\hline Sample & $S_{\mathrm{BET}}\left(\mathrm{m}^{2} \cdot \mathrm{g}^{-1}\right)$ & $V_{\mathrm{BET}}\left(\mathrm{cm}^{3} \cdot \mathrm{g}^{-1}\right)$ & $V_{\text {meso }}\left(\mathrm{cm}^{3} \cdot \mathrm{g}^{-1}\right)$ & $V_{\text {Micro }}(\mathrm{BET})\left(\mathrm{cm}^{3} \cdot \mathrm{g}^{-1}\right)$ & $V_{\text {Micro }}(\mathrm{DA})\left(\mathrm{cm}^{3} \cdot \mathrm{g}^{-1}\right)$ \\
\hline BC1 & 329.7 & 0.17 & 0.03 & 0.14 & 0.21 \\
BC2 & 364.2 & 0.26 & 0.14 & 0.15 & 0.26 \\
\hline
\end{tabular}

Table 3 shows the results of total surface area $\left(S_{\mathrm{BET}}\right)$ and total pore volume $\left(V_{\mathrm{BET}}\right)$, estimated by the BET method, and micropore volume $\left(V_{\text {Micro }}\right)$ and mesopore volume $\left(V_{\text {Meso }}\right)$, estimated by the $\mathrm{t}$-plot and $\mathrm{BJH}$ methods, respectively.

The $S_{\mathrm{BET}}$ of $\mathrm{BC} 2$ was higher than that of $\mathrm{BC} 1$ $\left(364.2 \mathrm{~m}^{2} \cdot \mathrm{g}^{-1}\right.$ vs. $\left.329.7 \mathrm{~m}^{2} \cdot \mathrm{g}^{-1}\right)$. Similarly, the pore volume of $\mathrm{BC} 2$ was $0.26 \mathrm{~cm}^{3} \cdot \mathrm{g}^{-1}$ compared to $0.17 \mathrm{~cm}^{3} \cdot \mathrm{g}^{-1}$ for $\mathrm{BC} 1$. Compared to other biomass chars produced under similar carbonization conditions, such as fern char [50] or cashew nutshell char [51], BCs produced in this study achieved higher porosity levels. The $V_{\text {Micro }}$ (estimated by BET technique) of $\mathrm{BC} 1$ and $\mathrm{BC} 2$ is similar. However, the large size of the $\mathrm{N}_{2}$ molecules prevents them from entering the ultramicropores, i.e., pores with diameters less than $1 \mathrm{~nm}$. Therefore, $\mathrm{CO}_{2}$ adsorption/desorption was performed to fully reflect the microporous structures of these BCs (Figure 11).

The adsorption/desorption isotherm plot of $\mathrm{CO}_{2}$ of $\mathrm{BC} 2$ is above that of $\mathrm{BC}$, indicating a higher micropore volume. Moreover, both isotherms showed hysteresis at lowpressure. This indicates that the $\mathrm{CO}_{2}$ molecules were in a metastable state, and the gas was not readily released at the level corresponding to the value of thermodynamic equilibrium at pressure decrease [52]. In other words, both BCs exhibited heterogeneous surface properties with bottleneck shapes at the micropore entrance. This pore shape is known to be favorable for long particule capture.

The $V_{\text {Micro }}$ (estimated by DA method) reached $0.26 \mathrm{~cm}^{3} \cdot \mathrm{g}^{-1}$ for BC2 and $0.21 \mathrm{~cm}^{3} \cdot \mathrm{g}^{-1}$ for BC1. The smaller kinetic diameter of $\mathrm{CO}_{2}(0.3 \mathrm{~nm})$ compared to $\mathrm{N}_{2}$ $(0.36 \mathrm{~nm})$ gave a much higher $V_{\text {Micro }}$ calculated by the DA method than by the t-plot method. This indicates that the microporous structures were better developed in rice husk biochar than in coir biochar.

\subsection{Biochar Adsorbability}

3.8.1. General Evaluation of BC1 Adsorbability with Methylene Blue (MB). Evaluation of the effect of $\mathrm{pH}$ on biochar 1 adsorbability of methylene blue was first performed. Experiments were carried out to evaluate the effect of varying $\mathrm{pH}$ values of dye solution on the ability of biochar to adsorb methylene blue ions. The results are shown in Figure 12.

The effect of $\mathrm{pH}$ on methylene blue adsorption was not significant for biochar 1 as there was little difference between the three efficiency lines. At $\mathrm{pH}=2$, the adsorbability of $\mathrm{BC} 1$ was however slightly weaker than at other $\mathrm{pH}$ values for the first hours of the time series, which accurately reflects the point of zero charge principle. The difference between the efficiency lines of $\mathrm{BC} 1$ was more distinct for the efficiency lines at $\mathrm{pH}=2$ and at other $\mathrm{pH}$ values. The efficiency reached $66 \%$ at $\mathrm{pH} 2$ and $87 \%$ at both $\mathrm{pH} 6$ and $\mathrm{pH} 12$ after 30 minutes of adsorption. When the adsorption time was increased to 1 hour, the adsorption efficiency showed similar differences, $87 \%$ at $\mathrm{pH} 2$ and $94 \%$ at the other two $\mathrm{pH}$ values. It was found that dye adsorption increases with $\mathrm{pH}$, with a maximum adsorption at $\mathrm{pH} 6$. This could be due to the fact that the surface of the adsorbent becomes negative at higher $\mathrm{pH}$ values, favoring the adsorption of positively charged $\mathrm{MB}$ cationic dye via electrostatic attraction. Moreover, there is a 


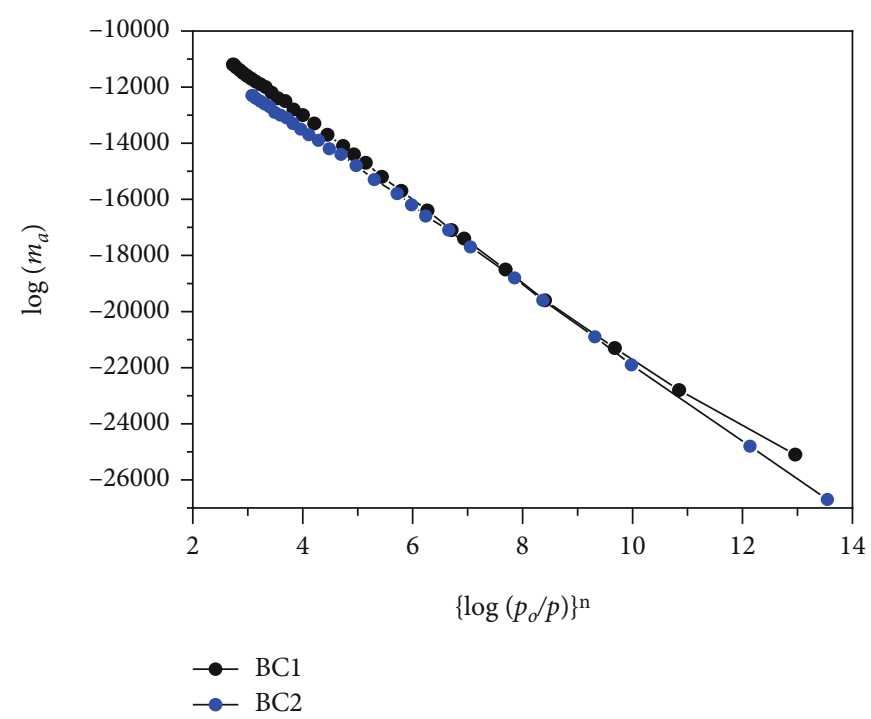

(a)

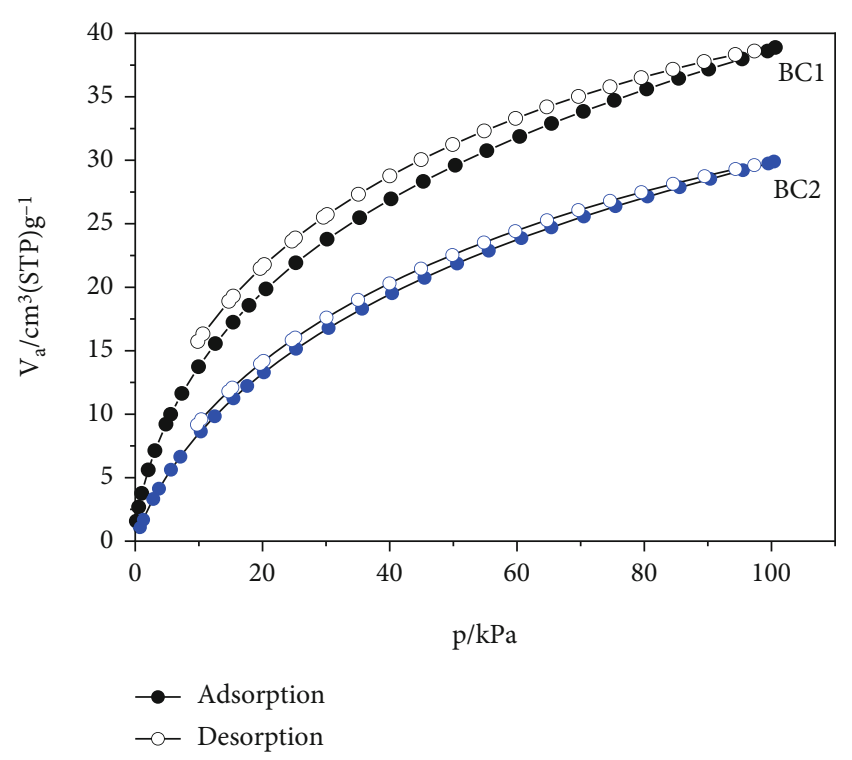

(b)

Figure 11: DA-plot (a) and adsorption/desorption isotherm (b) of $\mathrm{BC} 1$ and $\mathrm{BC} 2$ in $\mathrm{CO}_{2}$.

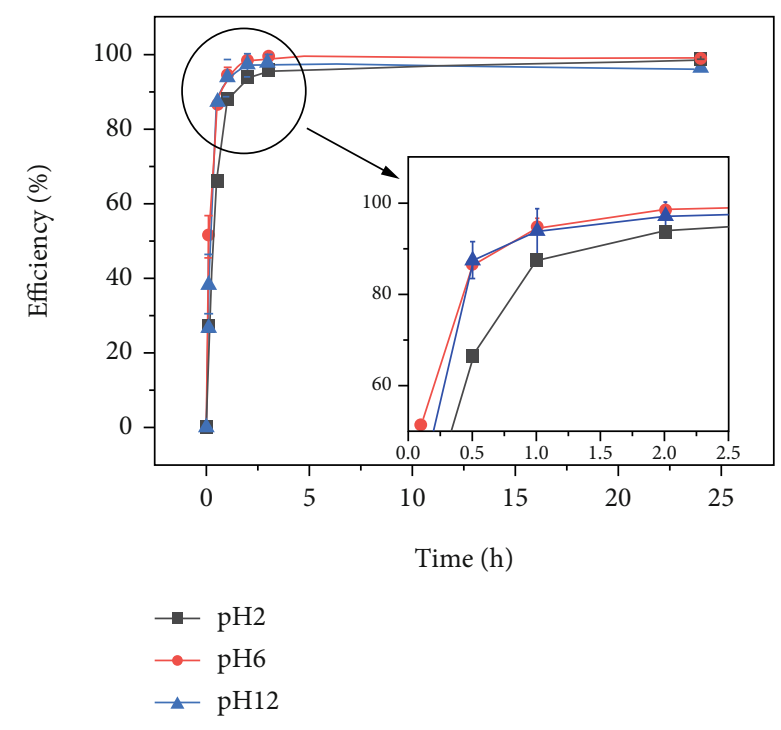

FIGURE 12: Evaluation of the effect of $\mathrm{pH}$ on biochar 1 ( 5 g.L $\left.\mathrm{L}^{-1}\right)$ adsorbability of methylene blue ions.

slight reduction in adsorption at $\mathrm{pH} 12$ due to the repulsion of adsorbent surface and the existence of a partial negative charge $\left(\mathrm{Cl}^{-}\right)$on $\mathrm{MB}[42]$.

3.8.2. Evaluation of the Effect of Biochar Dosage on Adsorbability with Methylene Blue. The effect of varying biochar concentration on the adsorption of dye ions on the biochar surface was studied with methylene blue. The results are given in Figure 13.

As expected, the higher the biochar concentration, the better the adsorbability. However, the differences are not really significant. Based on these results, a catalyst concentration of $5 \mathrm{~g} . \mathrm{L}^{-1}$ was selected for further studies.

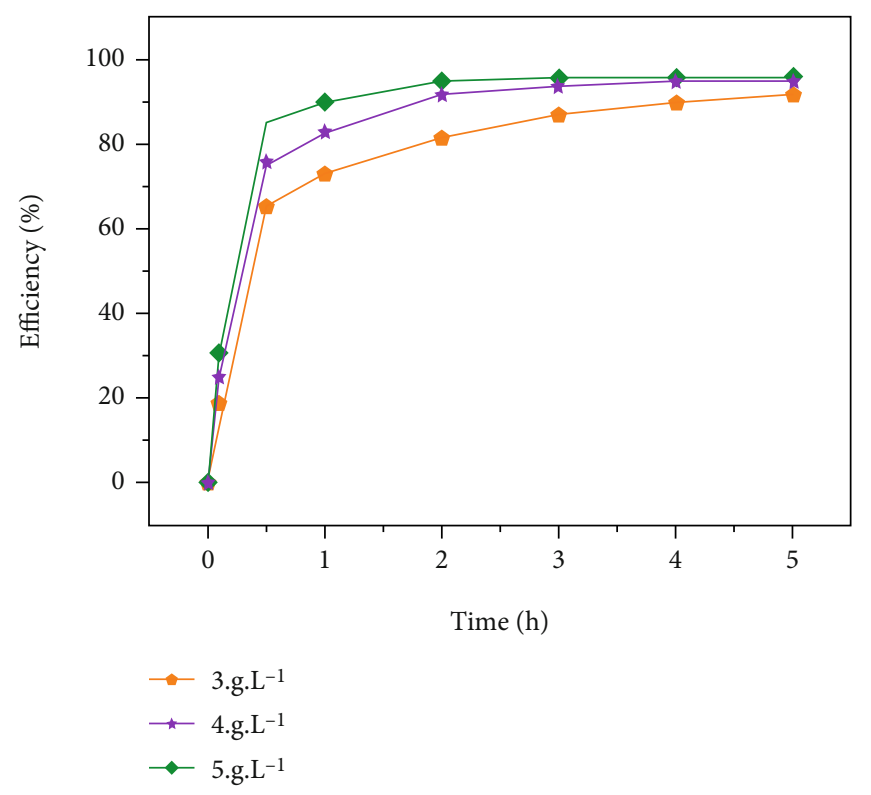

Figure 13: Evaluation of the effect of biochar 1 dosage on adsorbability.

3.8.3. Evaluation of the Effect of $\mathrm{pH}$ on Biochar Adsorbability with Methyl Orange. The laboratory-synthesized biochar BC1 was studied for its ability to remove not only methylene blue but also methyl orange, an anionic dye. The results are shown in Figure 14.

At $\mathrm{pH} 2$, it took less than an hour to reach $80 \%$ efficiency, and after 5 hours, biochar 1 had removed over $96 \%$ of the MO in the solution. In contrast, the efficiency of dye removal at $\mathrm{pH} 6$ and 12 was approximately half that at $\mathrm{pH} 2,49 \%$, and 47\%, respectively. At $\mathrm{pH} 6$ and $\mathrm{pH} 12$, the surface was, respectively, neutral and positively charged; therefore; adsorption efficiency is much lower. 


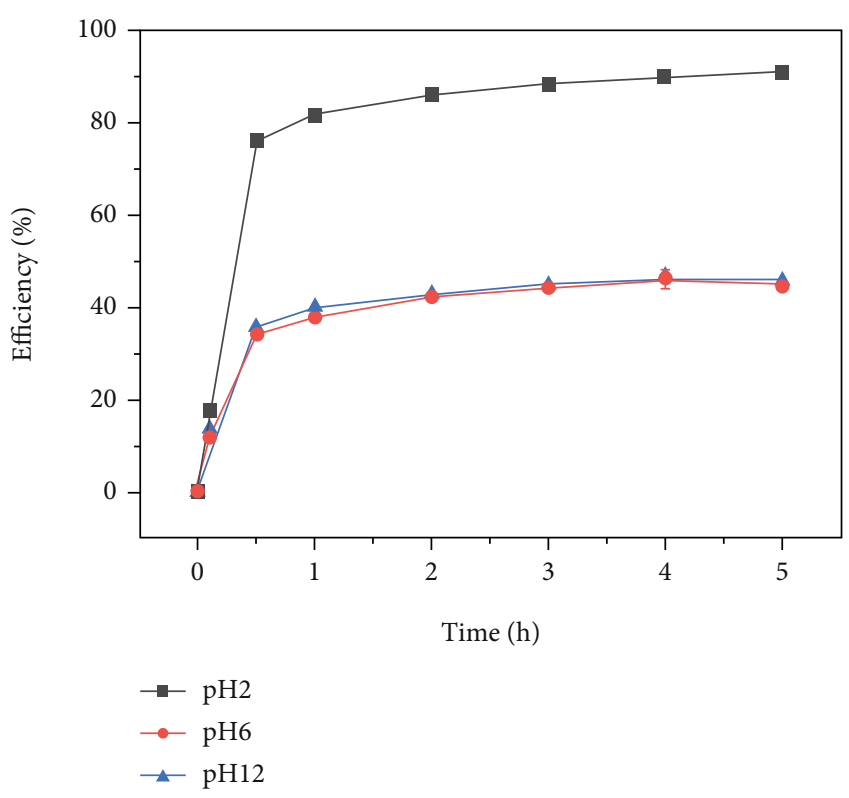

Figure 14: Evaluation of the effect of $\mathrm{pH}$ on biochar $1\left(5 \mathrm{~g} . \mathrm{L}^{-1}\right)$ adsorbability of methyl orange.

In addition to the electrostatic interaction following the PZC principle, many functional groups exist on the biochar surface and bind to methylene blue or methyl orange, thus, facilitating the adsorption on the biochar surface. When the $\mathrm{pH}$ of the solution was decreased significantly, the positive surface charge of the BC increased and, consequently, the adsorption of methyl orange anions on the $\mathrm{BC}$ surface increased significantly. On the contrary, when the $\mathrm{pH}$ of the solution was increased, the adsorption of methyl orange on $\mathrm{BC} 1$ decreased due to the repulsive force between the adsorbent and the negatively charged adsorbate. However, the adsorption of methylene blue at high $\mathrm{pH}$ was enhanced due to the strong electrostatic interaction between the cationic groups of $\mathrm{MB}$ molecule and the negatively charged BC surface. Therefore, this could be the main mechanism of the adsorption. The results showed that the highest adsorption efficiency of $\mathrm{BC}$ was obtained at basic $\mathrm{pH}$ values for $\mathrm{MB}$ and at acidic $\mathrm{pH}$ for $\mathrm{MO}$.

In consequence, the influence of the two different biochars on dye adsorbability was investigated at $\mathrm{pH} 6$ for $\mathrm{MB}$ and at $\mathrm{pH} 2$ for MO (Figure 15).

Figure 15 clearly demonstrates that the adsorption of $\mathrm{BC} 2$ was superior to that of $\mathrm{BC} 1$ under the same conditions with a peak efficiency of nearly $100 \%$. This difference is also partly due to the physical characteristics of the adsorbent. BC2 is derived from the rice husk with a much higher number of pores than BC1 which is coconut coir. It has both meso and micropores, so the total BET and total porous volume of BC2 are larger than $\mathrm{BC} 1,364.22 \mathrm{~m}^{2} \cdot \mathrm{g}^{-1}>329.71$ $\mathrm{m}^{2} \cdot \mathrm{g}^{-1}$ and $0.26 \mathrm{~m}^{2} \cdot \mathrm{g}^{-1}>0.17 \mathrm{~m}^{2} \cdot \mathrm{g}^{-1}$.

Moreover, biochar 2 has a relatively high microporous and mesoporous area, $0.15 \mathrm{~cm}^{3} \cdot \mathrm{g}^{1}$ and $0.14 \mathrm{~cm}^{3} \cdot \mathrm{g}^{-1} \mathrm{com}-$ pared to $0.14 \mathrm{~cm}^{3} \cdot \mathrm{g}^{-1}$ and $0.03 \mathrm{~cm}^{3} \cdot \mathrm{g}^{-1}$ for biochar 1 , respectively. Apart from those factors, these two types of biochar had similar surface functional groups, and the only difference was the silicon components found in $\mathrm{BC} 2$.

The MB adsorption efficiency of BC1 was close to $94 \%$, much higher than that of MO (about 82\%) after 1 hour of the reaction. $\mathrm{BC} 2$ also showed a similar trend with the adsorption efficiency slightly higher for $\mathrm{MB}$ than for $\mathrm{MO}$, about $100 \%$ and $96 \%$, respectively. Both materials had better electronic interactions with $\mathrm{MB}$ than with MO. This suggested that the adsorption capacity of both biochars was more efficient for $\mathrm{MB}$ than for MO. Considering the physicochemical properties of the adsorbent surface, although MO $(1.31 \times 0.55 \times 0.18 \mathrm{~nm})$ has a smaller molecular size than $\mathrm{MB}(1.26 \times 0.77 \times 0.65 \mathrm{~nm})$, which means that $\mathrm{MO}$ molecules were able to enter the pores and being retained in more micro and mesopores; however, $\mathrm{MB}$ ions were more selectively adsorbed.

This result is consistent with the study of Phuong et al. [53] who obtained an average surface area including micropore and mesopore of rice husk-derived biochar of 118 $\mathrm{m}^{2} \cdot \mathrm{g}^{-1}$. Since the volume of mesopore was quite small and most of the pore volume was micropore, $\mathrm{MB}$ ions took longer to be adsorbed into the BCA pores, so the adsorbability rate was slowed down. In our study, the dye adsorption rate of $\mathrm{BC} 1$ was slower than that of $\mathrm{BC} 2$ because $\mathrm{BC} 2$ had a larger BET volume and much larger pore volume, as mentioned above. Both dyes can be completely adsorbed.

3.8.4. Isothermal Adsorption. The results of the physicochemical characteristics analysis showed that BC2 had a higher adsorption capacity than $\mathrm{BC} 1$ due to its larger surface area and pore volume, a larger number of surface functional groups, and a lower $\mathrm{pH}$ of PZC. Therefore, the adsorption isotherm of $\mathrm{MB}$ and $\mathrm{MO}$ adsorption was also evaluated through two popular adsorption models, Langmuir and Freundlich isotherm models. Figure 16 shows the isotherm of $\mathrm{MB}$ and $\mathrm{MO}$ adsorption on $\mathrm{BC} 1$ material according to Langmuir and Freundlich models.

The parameters of Langmuir and Freundlich adsorption isotherms were calculated from the slope values and the vertical cut and are presented in Table 4.

Langmuir and Freundlich adsorption isotherms are two chemisorption models in which Langmuir is a monolayer adsorption process while Freundlich describes a multilayer adsorption capacity of the material.

The results demonstrated that the adsorption capacity of BC2 followed both Langmuir and Freundlich models with MO adsorbent. The regression coefficients $R^{2}$ were both high (0.97 and 0.99 for Langmuir and Freundlich, respectively), revealing that the adsorption process follows both models. In contrast, with the MB adsorbent, the adsorption isotherm followed the Langmuir model with a regression coefficient of 0.99. For BC1 adsorption, MO followed the Langmuir model with $R^{2}$ of 0.99 and $\mathrm{MB}$ followed Freundlich with the same $R^{2}$ value. Overall, in this study, the dye removal efficiency of $\mathrm{BC} 2$ was higher than that of $\mathrm{BC} 1$, both following the Langmuir and Freundlich isotherm models.

Remind that the Freundlich model suggests multilayer physisorption on the surface of the material with different adsorption energy levels whereas the Langmuir model 


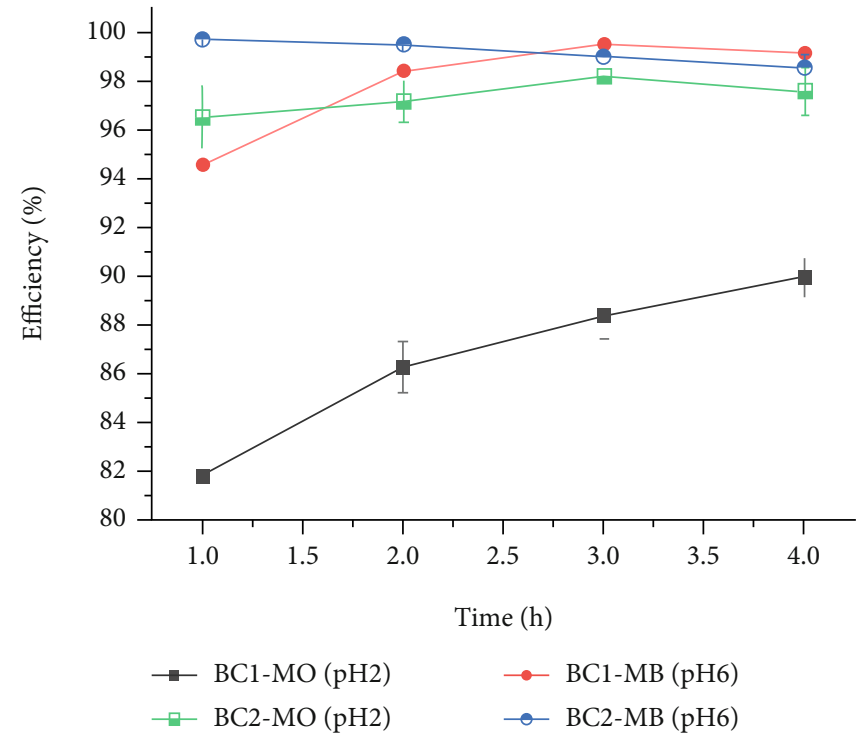

FIGURE 15: Effect of two different biochars on adsorbability of dyes molecules.

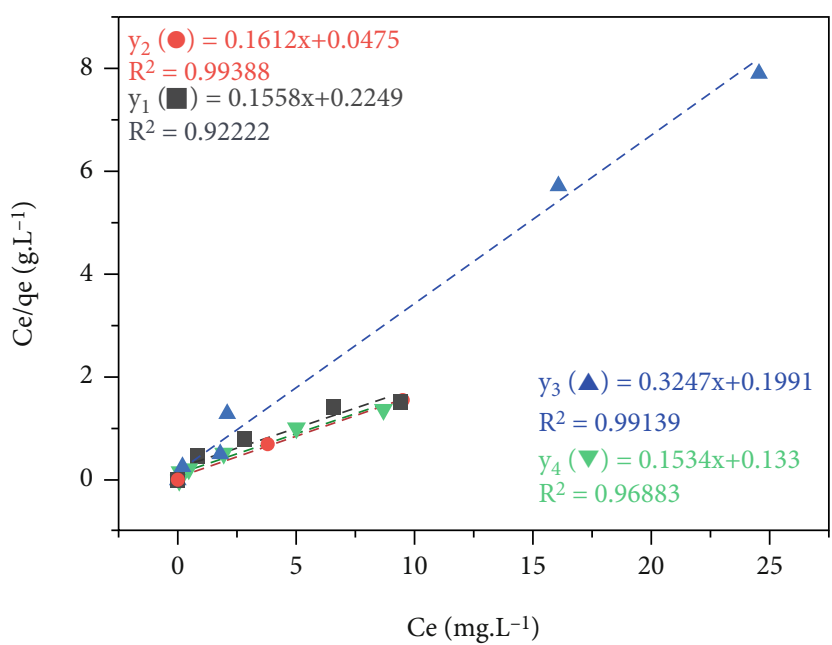

(a)

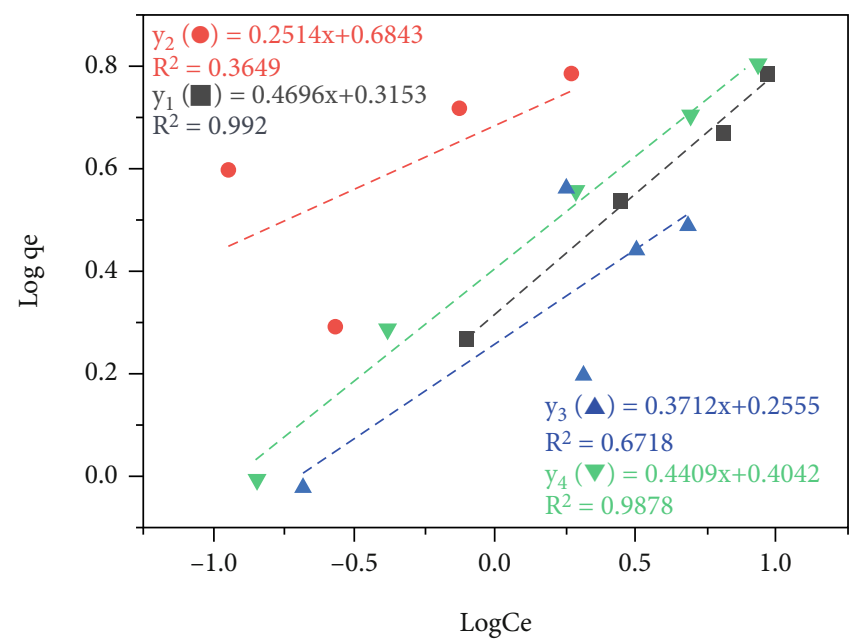

BCI-MB

$\mathrm{BC} 2-\mathrm{MB}$

(b)

Figure 16: Langmuir (a) and Freundlich (b) adsorption isotherm model fittings for the adsorption of $\mathrm{MB}$ and $\mathrm{MO}$ on $\mathrm{BC} 1$ and $\mathrm{BC} 2$ at $25^{\circ} \mathrm{C}$.

TABLE 4: The adsorption isotherm of MO and MB adsorbed on BC2 and BC2 materials according to Langmuir and Freundlich models.

\begin{tabular}{|c|c|c|c|c|c|}
\hline \multirow{2}{*}{ Model } & \multirow{2}{*}{ Parameters } & \multicolumn{2}{|c|}{$\mathrm{MB}$} & \multicolumn{2}{|c|}{$\mathrm{MO}$} \\
\hline & & $\mathrm{BC} 1$ & $\mathrm{BC} 2$ & BC1 & $\mathrm{BC} 2$ \\
\hline \multirow{3}{*}{ Langmuir isotherm parameters } & $R^{2}$ & 0.922 & 0.994 & 0.991 & 0.969 \\
\hline & $q_{\max }\left(\mathrm{mg} \mathrm{g}^{-1}\right)$ & 6.418 & 8.612 & 3.080 & 6.519 \\
\hline & $B\left(\mathrm{~L} \mathrm{mg}^{-1}\right)$ & 0.693 & 2.445 & 1.631 & 1.153 \\
\hline \multirow{3}{*}{ Freundlich isotherm parameters } & $R^{2}$ & 0.992 & 0.365 & 0.672 & 0.988 \\
\hline & 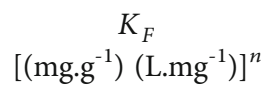 & 2.067 & 4.834 & 1.801 & 2.536 \\
\hline & $n$ & 2.129 & 3.978 & 2.694 & 2.268 \\
\hline
\end{tabular}


proposes monolayer chemisorption by the donor-acceptor interaction based on electrophilic addition [54, 55]. This was because the charge-rich carbonized surface created bonds with protonated amino groups in the acidic medium. In addition, $\mathrm{H}-\mathrm{H}$ and $\mathrm{H}-\mathrm{O}$ bonding between the carbonsilicon group on the surface of biochar with the phenolic group of dye molecules could also be able to occur [56].

Rodriguez also indicated that the mechanism of dye adsorption on biochars may be classified into two types of interactions: nonelectrostatic and electrostatic. Adsorption is affected by the $\mathrm{pH}$ of the solution as well as the $\mathrm{pH}_{\mathrm{PZC}}$. Therefore, at $\mathrm{pH}<\mathrm{pHpzc}$, the surface of the biochar is positively charged, promoting anionic species adsorption, and negatively charged at $\mathrm{pH}>\mathrm{pHpzc}$, favoring cationic species adsorption [57]. Furthermore, all biochar samples had pHpzc values of 8 and 9 for $\mathrm{BC} 1$ and $\mathrm{BC} 2$, respectively, higher than the $\mathrm{pH}$ values of $\mathrm{MB}(6.0)$ and $\mathrm{MO}(2)$ solutions. Biochar has a positive charge, $\mathrm{MB}$ is a cation dye that has a positive charge when dissolved in water, and $\mathrm{MO}$ is an anion dye that becomes negatively charged when dissolved in water. The adsorption mechanism is therefore dominated by the dispersion interaction between the dissociated electrons on the surface of the activated carbon and the free electrons of the dye molecule contained in the aromatic ring [58].

The $R_{L}$ separation factor values for dye adsorption on the particular adsorbent were all positive and less than unity in all cases, suggesting extremely favorable adsorption under all circumstances. This is furthermore consistent with the results for the $1 / n_{F}$ values, which were less than unity, suggesting that the dye is preferentially absorbed by biochar.

In terms of the maximum adsorption capacity of a material, BC2 adsorbs both dyes well and better than BC1 with a $q_{\max }$ value of $8.612{\mathrm{mg} . \mathrm{g}^{-1}}$ and $6.519 \mathrm{mg}^{-1}$ for $\mathrm{MB}$ and $\mathrm{MO}$, respectively. These values are was quite low compared to that of various adsorbents, such as bamboo-activated carbon [59], pea shells [60], modified clay-ball [61], and activated biochar derived from wakame [62]. However, biochars prepared with a particle size of $1-2 \mathrm{~mm}$ for coir and $5 \mathrm{~mm}$ for rice husk are more ecologically friendly and economically effective compared to other adsorbents. First, the granular nature of the adsorbent is useful since it can be easily separated after filtration and sedimentation without creating sludge. Second, in terms of recycling, using an agricultural by-product allows waste to be a valued resource to reduce environmental risks [12].

\section{Conclusions}

Biochars derived from agricultural by-products including coconut coir and rice husk were successfully produced in large quantity, homogenized following the calcination process, and then activated by $H 25 \%$. The biochars had a high specific surface area of $364.22 \mathrm{~m}^{2} \cdot \mathrm{g}^{-1}$ and $329.71 \mathrm{~m}^{2} \cdot \mathrm{g}^{-1}$ for rice husk and coconut coir biochars, respectively. All biochars had micro and mesopore structures but with different amounts. SEM images as well as XRD and Raman analysis of different biochars also showed various graphene layers with an amorphous structure. These results suggest that the bio- char obtained in this study could have a high adsorbability for small to large molecules. Indeed, both biochar BC1 and BC2 showed good adsorption ability for MB and MO. In addition, BC2 had a better performance in dye adsorption than $\mathrm{BC} 1$.

The results of adsorption isotherm experiments indicated BC2 material followed Langmuir and Freundlich isotherms when adsorbing MO with a maximal adsorption volume of $6.519 \mathrm{mg} \cdot \mathrm{g}^{-1}$. In the case of MB adsorption, BC2 only followed the Langmuir isotherm with a maximal adsorption volume of $8.612 \mathrm{mg}^{-1}$. On the contrary, BC1 adsorbed $\mathrm{MB}$ following the Freundlich isotherm while its MO adsorption followed the Langmuir isotherm. In general, the agricultural by-products can be reused after treatment as adsorbers for persistent organic pollutants, including those found in wastewater from the textile industry.

\section{Data Availability}

The data used to support the findings of this study are included in the article.

\section{Conflicts of Interest}

The authors declare that they have no conflicts of interest.

\section{Acknowledgments}

This research was funded by the Vietnam Academy of Science and Technology (VAST), code: VAST07.04/20-21. The authors wish to acknowledge the support of the International Joint Laboratory LOTUS (Land-Ocean aTmosphere regional coUpled System) as well as the Institute of Research of Environment (IRD). The authors greatly appreciate the editorial team as well as reviewers who have devoted their time and expertise to improve the quality of this publication.

\section{References}

[1] B. Nhung and T. Thuy, "Vietnam's textile and garment industry: an overview," in Business and IT, vol. VIII, no. 2, pp. 4553, 2018.

[2] K. Sarayu and S. Sandhya, "Current technologies for biological treatment of textile wastewater-a review," Applied Biochemistry and Biotechnology, vol. 167, no. 3, pp. 645-661, 2012.

[3] H. Wang, X.-W. Zheng, J.-Q. Su, Y. Tian, X.-J. Xiong, and T.L. Zheng, "Biological decolorization of the reactive dyes Reactive Black 5 by a novel isolated bacterial strain _Enterobacter sp. EC3," Journal of Hazardous Materials, vol. 171, no. 1-3, pp. 654-659, 2009.

[4] M. S. Mahmoud, J. Farah, and T. E. Farrag, "Enhanced Removal of Methylene Blue by Electrocoagulation Using Iron Electrodes," Egyptian Journal of Petroleum, vol. 22, no. 1, pp. 211-216, 2013.

[5] A. S. Naje, S. Chelliapan, Z. Zakaria, M. A. Ajeel, and P. A. Alaba, "A review of electrocoagulation technology for the treatment of textile wastewater," Reviews in Chemical Engineering, vol. 33, pp. 263-292, 2017.

[6] U. Tezcan Un and E. Aytac, "Electrocoagulation in a packed bed reactor-complete treatment of color and cod from real 
textile wastewater," Journal of Environmental Management, vol. 123, pp. 113-119, 2013.

[7] V. Jegatheesan, B. K. Pramanik, J. Chen, D. Navaratna, C.Y. Chang, and L. Shu, "Treatment of textile wastewater with membrane bioreactor: a critical review," Bioresource Technology, vol. 204, pp. 202-212, 2016.

[8] A. H. Konsowa, M. G. Eloffy, and Y. A. El-Taweel, "Treatment of dyeing wastewater using submerged membrane bioreactor," Desalination Water Treat, vol. 51, no. 4-6, pp. 1079-1090, 2013.

[9] B. X. Thanh, N. P. Dan, and N. T. Binh, "Fouling mitigation in a submerged membrane bioreactor treating dyeing and textile wastewater," Desalination Water Treat, vol. 47, no. 1-3, pp. 150-156, 2012.

[10] M. R. Al-Mamun, S. Kader, M. S. Islam, and M. Z. H. Khan, "Photocatalytic activity improvement and application of UV$\mathrm{TiO}_{2}$ photocatalysis in textile wastewater treatment: a review," Journal of Environmental Chemical Engineering, vol. 7, no. 5, p. 103248, 2019.

[11] A. Sharma, Z. Syed, U. Brighu, A. B. Gupta, and C. Ram, "Adsorption of textile wastewater on alkali-activated sand," Journal of Cleaner Production, vol. 220, pp. 23-32, 2019.

[12] J. O. Quansah, T. Hlaing, F. N. Lyonga et al., "Nascent rice husk as an adsorbent for removing cationic dyes from textile wastewater," Applied Sciences, vol. 10, no. 10, p. 3437, 2020.

[13] B. Srivastava, V. Jhelum, D. D. Basu, and P. K. Patanjali, "Adsorbent for pesticide uptake from contaminated water: a review," Journal of Scientific and Industrial Research, vol. 68, pp. 839-850, 2009.

[14] A. Bhatnagar and M. Sillanpää, "Utilization of agro-industrial and municipal waste materials as potential adsorbents for water treatment-a review," Chemical Engineering Journal, vol. 157, no. 2-3, pp. 277-296, 2010.

[15] M. Akhtar, S. M. Hasany, M. I. Bhanger, and S. Iqbal, "Low cost sorbents for the removal of methyl parathion pesticide from aqueous solutions," Chemosphere, vol. 66, no. 10, pp. 1829-1838, 2007.

[16] S. Deokar and S. Mandavgane, "Rice husk ash for fast removal of 2,4-dichlorophenoxyacetic acid from aqueous solution," Adsorption Science and Technology, vol. 33, no. 5, pp. 429$440,2015$.

[17] M. L. Firdaus, N. Krisnanto, W. Alwi, R. Muhammad, and M. A. Serunting, "Adsorption of textile dye by activated carbon made from rice straw and oil palm midrib," Aceh International Journal of Science and Technology, vol. 6, no. 1, pp. 1-7, 2017.

[18] M. Ghorbani and H. Eisazadeh, "Removal of COD, color, anions and heavy metals from cotton textile wastewater by using polyaniline and polypyrrole nanocomposites coated on rice husk ash," Composites. Part B, Engineering, vol. 45, no. 1, pp. 1-7, 2013.

[19] M. Muneer, I. A. Bhatti, and S. Adeel, "Removal of $\mathrm{Zn}, \mathrm{Pb}$ and Cr in textile wastewater using rice husk as a biosorbent," Asian Journal of Chemistry, vol. 22, pp. 7453-7459, 2010.

[20] I. Herath, P. Kumarathilaka, M. I. Al-Wabel et al., "Mechanistic modeling of glyphosate interaction with rice husk derived engineered biochar," Microporous and Mesoporous Materials, vol. 225, pp. 280-288, 2016.

[21] Y. C. Sharma and S. N. Upadhyay, "An economically viable removal of methylene blue by adsorption on activated carbon prepared from rice husk," Canadian Journal of Chemical Engineering, vol. 89, no. 2, pp. 377-383, 2011.
[22] J. S. Chin-Pampillo, K. Ruiz-Hidalgo, M. Masís-Mora, E. Carazo-Rojas, and C. E. Rodríguez-Rodríguez, "Design of an optimized biomixture for the degradation of carbofuran based on pesticide removal and toxicity reduction of the matrix," Environmental Science and Pollution Research, vol. 22, no. 23, pp. 19184-19193, 2015.

[23] T. De Wilde, P. Spanoghe, J. Ryckeboer, P. Jaeken, and D. Springael, "Sorption characteristics of pesticides on matrix substrates used in biopurification systems," Chemosphere, vol. 75, no. 1, pp. 100-108, 2009.

[24] G. D. Gikas, M. Pérez-Villanueva, M. Tsioras et al., "Lowcost approaches for the removal of terbuthylazine from agricultural wastewater: constructed wetlands and biopurification system," Chemical Engineering Journal, vol. 335, pp. 647-656, 2018.

[25] A. K. Samanta, G. Basu, and L. Mishra, "Role of major constituents of coconut fibres on absorption of ionic dyes," Industrial Crops and Products, vol. 117, pp. 20-27, 2018.

[26] N. L. P. A. Saraswati and I. D. K. Sastrawidana, "Absorption of Remazol Red dye from textile waste using activated carbon from coconut shell," IOP Conference Series: Materials Science and Engineering, vol. 1115, no. 1, article 012076, 2021.

[27] Y. C. Wong, M. S. R. Senan, and N. A. Atiqah, "Removal of methylene blue and malachite green dye using different form of coconut fibre as absorbent," Journal of Basic \& Applied Sciences, vol. 9, pp. 172-177, 2013.

[28] A. Demirbas, "Agricultural based activated carbons for the removal of dyes from aqueous solutions: a review," Journal of Hazardous Materials, vol. 167, no. 1-3, pp. 1-9, 2009.

[29] T. Ahmad, M. Rafatullah, A. Ghazali, O. Sulaiman, R. Hashim, and A. Ahmad, "Removal of pesticides from water and wastewater by different adsorbents: a review," Journal of Environmental Science and Health, Part C, vol. 28, no. 4, pp. 231271, 2010.

[30] O. A. Ioannidou, A. A. Zabaniotou, G. G. Stavropoulos, M. A. Islam, and T. A. Albanis, "Preparation of activated carbons from agricultural residues for pesticide adsorption," Chemosphere, vol. 80, no. 11, pp. 1328-1336, 2010.

[31] S. P. Sohi, E. Krull, E. Lopez-Capel, and R. Bol, "A review of biochar and its use and function in soil," Advances in agronomy, vol. 105, pp. 47-82, 2010.

[32] H. Cederlund, E. Börjesson, and J. Stenström, "Effects of a wood-based biochar on the leaching of pesticides chlorpyrifos, diuron, glyphosate and MCPA," Journal of Environmental Management, vol. 191, pp. 28-34, 2017.

[33] M. Hagner, S. Hallman, L. Jauhiainen et al., "Birch (Betula spp) wood biochar is a potential soil amendment to reduce glyphosate leaching in agricultural soils," Journal of Environmental Management, vol. 164, pp. 46-52, 2015.

[34] X. Jiang, Z. Ouyang, Z. Zhang et al., "Mechanism of glyphosate removal by biochar supported nano-zero-valent iron in aqueous solutions," Colloids and Surfaces A: Physicochemical and Engineering Aspects, vol. 547, pp. 64-72, 2018.

[35] S. S. Mayakaduwa, P. Kumarathilaka, I. Herath et al., "Equilibrium and kinetic mechanisms of woody biochar on aqueous glyphosate removal," Chemosphere, vol. 144, pp. 2516-2521, 2016.

[36] S. De Gisi, G. Lofrano, M. Grassi, and M. Notarnicola, "Characteristics and adsorption capacities of low-cost sorbents for wastewater treatment: a review," Sustainable Materials and Technologies, vol. 9, pp. 10-40, 2016. 
[37] Z.-L. Chen, J.-Q. Zhang, L. Huang, Z.-H. Yuan, Z.-J. Li, and M.-C. Liu, "Removal of $\mathrm{Cd}$ and $\mathrm{Pb}$ with biochar made from dairy manure at low temperature," Journal of Integrative Agriculture, vol. 18, no. 1, pp. 201-210, 2019.

[38] Q.-P. Zhang, Q.-C. Liu, B. Li et al., "Adsorption of Cd(II) from aqueous solutions by rape straw biochar derived from different modification processes," Chemosphere, vol. 175, pp. 332-340, 2017.

[39] H. Pouretedal and N. Sadegh, "Effective removal of amoxicillin, cephalexin, tetracycline and penicillin G from aqueous solutions using activated carbon nanoparticles prepared from vine wood," Journal of Water Process Engineering, vol. 1, pp. 64-73, 2014.

[40] P. K. Malik, "Dye removal from wastewater using activated carbon developed from sawdust: adsorption equilibrium and kinetics," Journal of Hazardous Materials, vol. 113, no. 1-3, pp. 81-88, 2004.

[41] B. A. T. Mehrabadi, S. Eskandari, U. Khan, R. D. White, and J. R. Regalbuto, "A review of preparation methods for supported metal catalysts," Advances in catalysis, vol. 61, pp. 135,2017

[42] P. Sharma, R. Kaur, C. Baskar, and W.-J. Chung, "Removal of methylene blue from aqueous waste using rice husk and rice husk ash," Desalination, vol. 259, no. 1-3, pp. 249-257, 2010.

[43] K. Zhang, P. Sun, M. C. A. S. Faye, and Y. Zhang, "Characterization of biochar derived from rice husks and its potential in chlorobenzene degradation," Carbon, vol. 130, pp. 730-740, 2018.

[44] M. Zhang, B. Gao, Y. Yao, Y. Xue, and M. Inyang, "Synthesis, characterization, and environmental implications of graphene-coated biochar," Science of the Total Environment, vol. 435-436, pp. 567-572, 2012.

[45] G. E. Tranter and D. D. Le Pevelen, "Chiroptical spectroscopy and the validation of crystal structure stereochemical assignments," Tetrahedron Asymmetry, vol. 28, pp. 1192-1198, 2017.

[46] A. B. Fuertes, M. C. Arbestain, M. Sevilla et al., "Chemical and structural properties of carbonaceous products obtained by pyrolysis and hydrothermal carbonisation of corn stover," Soil Research, vol. 48, no. 7, pp. 618-626, 2010.

[47] E. Pusceddu, S. F. Santilli, G. Fioravanti, A. Montanaro, F. Miglietta, and P. U. Foscolo, "Chemical-physical analysis and exfoliation of biochar-carbon matter: from agriculture soil improver to starting material for advanced nanotechnologies," Materials Research Express, vol. 6, no. 11, p. 115612, 2019.

[48] H. N. Nguyen, D. A. Khuong, T. T. H. Vu et al., "Kinetic and structural changes during gasification of cashew nut shell char particles," Environmental Progress \& Sustainable Energy, vol. 40, no. 3, article e13580, 2021.

[49] J. B. Condon, Surface Area and Porosity Determinations by Physisorption: Measurement, Classical Theories and Quantum Theory, Elsevier, 2006.

[50] A. T. Q. Nguyen, T. A. Bui, N. T. Mai et al., "Release kinetics of potassium from silica-rich fern-derived biochars," Agronomy Journal, vol. 112, no. 3, pp. 1713-1725, 2020.

[51] N. H. Nam, K. D. Anh, L. G. T. Truc, T. A. Ha, and V. T. T. Ha, "Pyrolysis of cashew nut shell: a parametric study," Vietnam Journal of Chemistry, vol. 58, pp. 506-511, 2020.

[52] M. Abunowara, M. A. Bustam, S. Sufian, and U. Eldemerdash, "Description of carbon dioxide adsorption and desorption onto Malaysian coals under subcritical condition," Procedia engineering, vol. 148, pp. 600-608, 2016.
[53] H. T. Phuong, M. A. Uddin, and Y. Kato, "Characterization of biochar from pyrolysis of rice husk and rice straw," Journal of Biobased Materials and Bioenergy, vol. 9, no. 4, pp. 439-446, 2015.

[54] H. M. F. Freundlich, "Over the adsorption in solution," The Journal of Physical Chemistry, vol. 57, pp. 385-471, 1906.

[55] I. Langmuir, "The constitution and fundamental properties of solids and liquids Part I. Ssolids," Journal of the American chemical society, vol. 38, no. 11, pp. 2221-2295, 1916.

[56] S. S. Mayakaduwa, M. Vithanage, A. Karunarathna, D. Mohan, and Y.S. Ok, "Interface interactions between insecticide carbofuran and tea waste biochars produced at different pyrolysis temperatures," Chemical Speciation \& Bioavailability, vol. 28, no. 1-4, pp. 110-118, 2016.

[57] F. Rodríguez-reinoso, "The role of carbon materials in heterogeneous catalysis," Carbon, vol. 36, no. 3, pp. 159-175, 1998.

[58] M. Belhachemi and F. Addoun, "Comparative adsorption isotherms and modeling of methylene blue onto activated carbons," Applied Water Science, vol. 1, no. 3-4, pp. 111-117, 2011.

[59] Q.-S. Liu, T. Zheng, N. Li, P. Wang, and G. Abulikemu, "Modification of bamboo-based activated carbon using microwave radiation and its effects on the adsorption of methylene blue," Applied Surface Science, vol. 256, no. 10, pp. 3309-3315, 2010.

[60] Ü. Geçgel, G. Özcan, and G. Ç. Gürpınar, "Removal of methylene blue from aqueous solution by activated carbon prepared from pea shells (Pisum sativum)," Journal of Chemistry, vol. 2012, Article ID 614083, 2010.

[61] M. Auta and B. H. Hameed, "Modified mesoporous clay adsorbent for adsorption isotherm and kinetics of methylene blue," Chemical Engineering Journal, vol. 198-199, pp. 219-227, 2012.

[62] X. Yao, L. Ji, J. Guo et al., "An abundant porous biochar material derived from wakame (Undaria pinnatifida) with high adsorption performance for three organic dyes," Bioresource Technology, vol. 318, p. 124082, 2020. 